\title{
Concurrent Occurrence of Fatty Liver Haemorrhagic Syndrome (FLHS) and Colisepticaemia in a Broiler Breeder Flock
}

\author{
Samir Dey ${ }^{1 *}$, M.C. Pakhira ${ }^{2}$, Kunal Batabyal ${ }^{1}$, Devi Prasad Isore ${ }^{1}$ and \\ Indranil Samanta ${ }^{1}$ \\ ${ }^{1}$ Department of Veterinary Microbiology, West Bengal University of Animal and Fishery \\ Sciences, Kolkata-700037, India \\ ${ }^{2}$ Department of Livestock Farm Complex, West Bengal University of Animal and Fishery \\ Sciences, Mohanpur, Nadia-741252, India
}

*Corresponding author

\section{A B S T R A C T}

\begin{tabular}{|l|}
\hline K e y w o r d s \\
Broiler, Disease, Farm, \\
$\begin{array}{l}\text { Fatty liver haemorrhagic } \\
\text { syndrome, Hen, West } \\
\text { Bengal }\end{array}$ \\
\hline Article Info \\
\hline $\begin{array}{l}\text { Accepted: } \\
\text { 04 August } 2018 \\
\text { Available Online: } \\
\text { 10 September } 2018\end{array}$ \\
\hline
\end{tabular}

Keywords

Broiler, Disease, Farm,

Bengal

Fatty liver haemorrhagic syndrome (FLHS) in poultry is a non-infectious metabolic disease of unknown aetiology. An outbreak of fatty liver haemorrhagic syndrome (FLHS) was detected at post mortem from 42-week old caged Vencobb broiler breeders in a commercial farm $(n=1200)$ of Bankura, West Bengal, India. The affected flock was showing severe loss of production and sudden death in peak summer month of June with $4 \%$ mortality in a week. Post mortem of the dead birds were performed and bacteriological examination were done as per standard procedure. At necropsy, dead birds had pale combs and wattles with significant liver lesions. The liver was enlarged, friable and greasy, yellowish brown with firm fatty layer deposits and haematoma was noticed in abdominal cavity. Escherichia coli was isolated in bacteriological examination of liver and spleen. Multiple factors like high dietary energy, stress of production and high ambient temperature may have precipitated the FLHS in broiler breeder hens.

\section{Introduction}

Fatty liver haemorrhagic syndrome (FLHS) is a non-infectious metabolic disease of hens that occurs mostly in caged layers fed on highenergy diets, which results in an increased accumulation of fat in the liver, liver rupture and sudden death (Crespo and Shivaprasad, 2008; Rozenboim et al., 2016).

In one overseas study, $74 \%$ of the total mortality in caged layers was reported due to FLHS in Queensland, Australia (Shini, 2014).
Considering commercial layers and broiler breeders are conventionally reared in cages, FLHS is a major cause of mortality and decreased egg production in affected flocks resulting in great economic losses to the poultry industry. However, FLHS is not limited to caged hens as the disease have been reported in free-range backyard poultry in USA (Trott et al., 2014) and found to be the most common non-infectious cause of mortality in laying backyard chickens in northern California (Mete et al., 2013; Crespo and Senties-Cue, 2015) 
FLHS is caused by diverse nutritional, hormonal, environmental and metabolic factors. Excessive consumption of highenergy diets combined with restricted activity is believed to result in fatty liver haemorrhagic syndrome, a condition of disturbed metabolism leading to excessive fat deposition in the liver (Rozenboim et al., 2016).

The pathogenesis of the haemorrhage associated with this syndrome is yet to be identified. However, the haemorrhage may result from the rupture of hepatic reticulin and capsule due to the excessive liver swelling caused by accumulation of fat (Hansen and Walzem, 1995). Experimentally, high dietary fat have been found to induce macroscopic and microscopic changes in liver of broilers (Qureshi et al., 2004). There are no comprehensive data available on the incidence of from commercial or backyard poultry in India. The disease is often neglected because of its sporadic incidence with low mortality. Fatty liver haemorrhagic syndrome was reported to be the cause of mortality in poultry occasionally in India (Davis et al., 2012). In one study, FLHS was recorded in $3.01 \%$ from 9755 birds during post mortem examination of 1985-1993 (Reddy et al., 1995). In the current study, we report an outbreak of FLHS in broiler breeders in a commercial farm of Bankura, West Bengal, India.

\section{Materials and Methods}

\section{Case history}

An incidence of FLHS was observed in commercial broiler breeder Vencobb hens $(n=$ 1200) aged 42-week-old during peak summer month of June with an ambient temperature $40^{\circ} \mathrm{C}-41^{\circ} \mathrm{C}$ in the district of Bankura, West Bengal with a history of an increased daily mortality, reduced egg production, yolk pasted vent, and mortality up to $4 \%$ in a span of 7 days. The flock was being fed a commercial layer diet and water ad libitum. This paper describes the pathological lesions and diagnostic findings of the flock. After necropsy, samples of the liver and spleen from birds were taken for bacteriological examination onto MacConkey agar and blood agar plates (HiMedia, India) and incubated aerobically at $37^{\circ} \mathrm{C}$ overnight.

\section{Results and Discussion}

Gross pathology of dead birds had pale combs and wattles, and greenish faecal stained feathers around the vent. The liver was highly enlarged, friable and greasy, yellowish brown with firm fatty layer deposits (Figure 1). A large amount of blood clots (haematoma) was also noticed in abdominal cavity. Large amount of fat deposits were also observed in abdominal cavity. Isolations of Escherichia coli were also made from the internal organs of birds (Figure 2). FLHS is currently diagnosed only after post mortem at necropsy (Yousefi et al., 2005). The gross appearance of FLHS was similar to those seen in previous investigations (Tablante et al., 1994).

Despite considerable research over the past few decades, the aetiology of the syndrome is still not completely understood. Multiple factors were incriminated in this disorder involving nutritional, environmental, genetic and hormonal factors (Hansen and Walzem, 1993; Whitehead, 1979).

Overcrowding, high ambient temperature, ammonia level, cage system in commercial layer management may be predisposing birds to FLHS (Tablante et al., 1994). Like our study, most previous investigators have reported that FLHS have significantly higher incidence in caged hens than in hens kept in other systems (Shini, 2014). However, a few studies have suggested that FLHS occurs equally in both caged and floor birds (Crespo and Shivaprasad, 2008; Trott et al., 2014). 


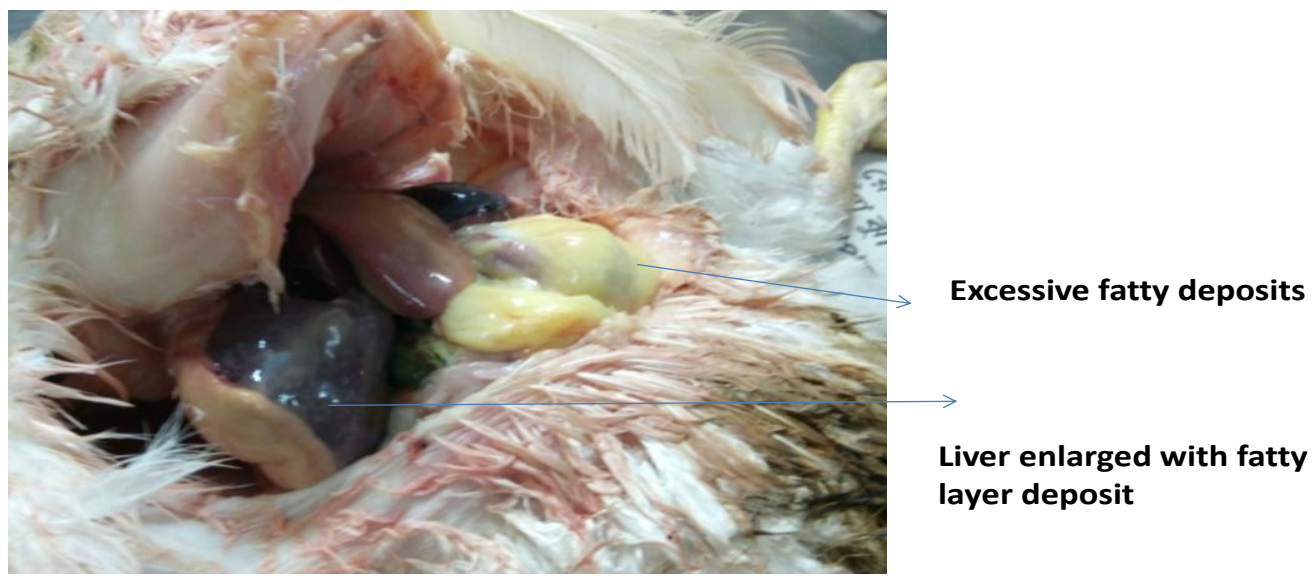

Figure 1: Fatty liver haemorragic syndrome in a broiler breeder hen

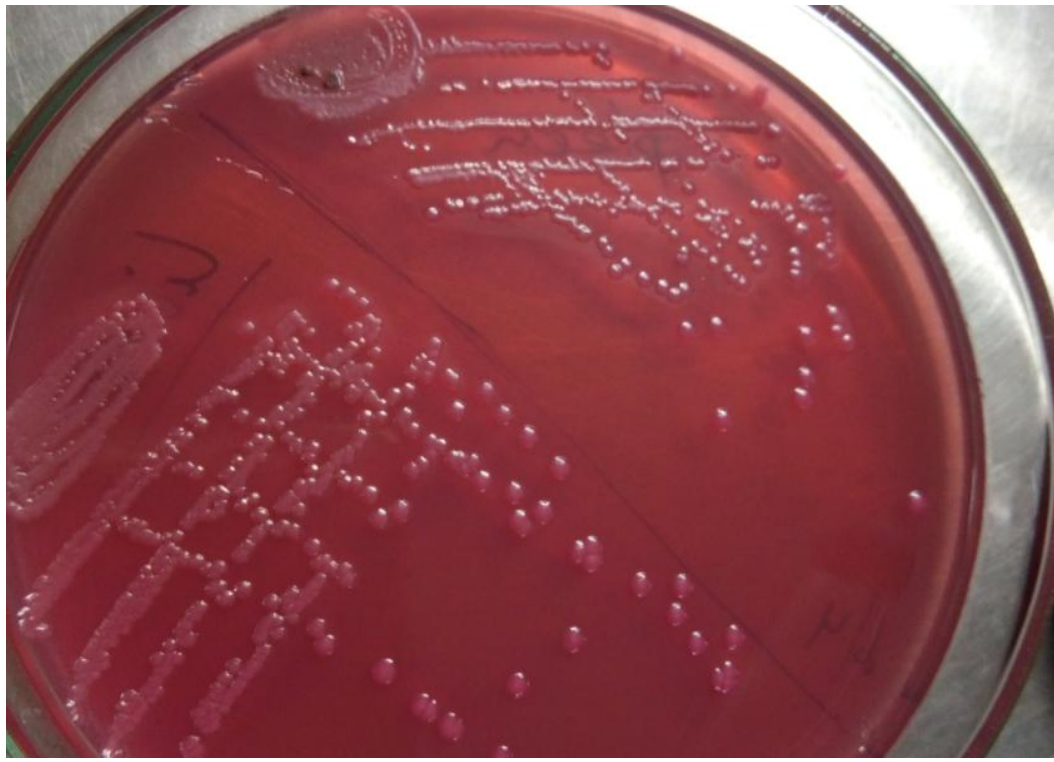

Figure 2: Lactose fermenting Escherichia coli colonies on MacConkey agar

Low protein in the diet with higher metabolisable energy from fat may be predisposing in White Leghorn laying hens to FLHS (Rozenboim et al., 2016). Higher incidence of FLHS was reported due to consumption of chelated minerals in hen than those consumed non-chelated minerals (Branton et al., 1995). Dietary soyabean phospholipids have been found to improve hepatic and blood lipid profile indexes relevant to FLHS (Yang et al., 2017). Dietary supplement of lipotropic agents containing 
choline were found helpful for remedy of FLHS (Onel et al., 2017). Supplementation of diet with Bio choline, choline chloride and lecithin extract have been found to have significantly decreased hepatic lipid concentration (Khosravinia et al., 2015).

Like our study, past researchers also found increased mortality due to FLHS at higher ambient temperature (Reddy et al., 1995) but temperature factor may be of secondary importance (Pearson and Butler, 1978). In accordance with our study, Agunos et al., (2006) also isolated Escherichia coli in liver of birds with FLHS. The exact role of colisepticaemia in the pathogenesis of fatty liver haemorrhagic syndrome was not clear. Bacterial endotoxin probably has no significant role with several parameters like haemorrhage score, the triglyceride content of the liver or plasma enzyme profile in poultry (Pearson et al., 1981).

The association of FLHS with birds that are in active stage of laying indicated that there is a hormonal involvement in the disorder. In one study, exogenous estrogen in growing male chicks have been found to induced hepatic fat accumulation, which might be partially due to increased lipogenic enzyme gene expression (Choi et al., 2012). Therefore, multiple factors like high dietary energy, stress of production and high ambient temperature may have precipitated the FLHS in broiler breeder Vencobb hens and need to be alleviated for effective control.

\section{Acknowledgments}

The authors are grateful to the Hon'ble ViceChancellor, Director of Research, West Bengal University of Animal and Fishery Sciences and Dean, Faculty of Veterinary Science for providing necessary facilities and Indian Council of Agricultural Research for financial assistance (Development Grant 7.1).

\section{References}

Agunos A.C., Yoo D., Youssef S.A, Ran D., Binnington B. and Hunter D.B. 2006. Avian hepatitis $\mathrm{E}$ virus in an outbreak of hepatitis-splenomegaly syndrome and fatty liver haemorrhage syndrome in two flaxseed-fed layer flocks in Ontario. Avian Pathol., 35(5): 404-412.

Branton S.L., Lott B.D, Maslin W.R. and Day E.J. 1995. Fatty liver- haemorrhagic syndrome observed in commercial layer fed diets containing chelated minerals. Avian Dis. 39(3): 631-35.

Choi Y.I., Ahn H.J., Lee B.K., Oh S.T., An B.K. and Kang C. W. 2012. Nutritional and hormonal induction of fatty liver syndrome and effects of dietary lipotropic factors in egg-type male chicks. Asian-Australasian J. Anim. Sci., 25(8): 1145 - 1152.

Crespo R. and Senties-Cue G. 2015. Post mortem survey of disease conditions in backyard poultry. J. Exotic Pet Med. 24: 156-163.

Crespo, R., and Shivaprasad, H.L.2008. Developmental, metabolic, and other noninfectious disorders, In: Diseases of Poultry, 12 ed., Chap.30, Blackwell Publishing Limited, United Kingdom, pp. 1173-74.

Davis, Daly C, Abraham, Mammen J., Lalithakunjamma, C. R., Divakaran Nair, N., Vijayan, N. 2012. Nutritional and metabolic diseases associated with hepato - renal pathology in chicken. Indian J. Anim.Res. 46 (4): 397-400.

Hansen, R. J., and R. L. Walzem. 1993. Avian fatty liver hemorrhagic syndrome: a comparative review. Adv. Vet. Sci. Comp. Med., 37: 451-468.

Khosravinia H, Chethen PS, Umakantha B. and Nourmohammadi R. 2015. Effects of lipotropic products on productive performance, liver lipid and enzymes 
activity in broiler chickens. Poult.Sci. J., 3 (2): 113-120.

Mete, A., Giannitti A.F., Barr B., Woods L. and Anderson M. 2013. Case report causes of mortality in backyard chickens in Northern California: 2007 2011. Avian Dis. 57(2): 311-15

Onel S.E., Sunger S. and Baylan M. 2017. Effect of supplementary choline on quail meat and fatty liver. Rev. Bras. Zootec. 46(8): 645-51.

Pearson, A.W. and Butler, E.J. 1978. Environmental temperature as a factor in the aetiology of fatty liverhaemorrhagic syndrome in the fowl. Res. Vet. Sci.25, 133-138.

Pearson, A.W., Curtis, M.J., Butler, E.J., 1981. Bacterial endotoxins and the pathogenesis of fatty liver-haemorrhagic syndrome in the laying hen. Res. Vet. Sci.31, 259-261.

Qureshi I.A., Khan S.A., Chaudhry Z.I., Mian N.A., Tipu M.Y. and M. F. Rai M.F. 2004. Effects of high dietary fat on serum cholesterol and fatty liver syndrome in broilers. Pakistan Vet. J., 24(3): 153-54.

Reddy, K.P., B. Sivaramakrishna and K. Radhakrishniah, 1995. Incidence of fatty liver haemorrhagic syndrome in broiler chicken. Poult. Adviser, 28(4): 21-23

Rozenboim I, Mahato J., Cohen N.A. and Tirosh O. 2016. Low protein and highenergy diet: a possible natural cause of fatty liver hemorrhagic syndrome in caged White Leghorn laying hens. Poult. Sci., 95:612-621.
Shini A. 2014. Fatty Liver Haemorrhagic Syndrome in Laying Hens: Field and Experimental Investigations. $\mathrm{PhD}$ Thesis, School of Agriculture and Food Sciences, The University of Queensland, Australia. doi:10.14264/uq1.2015.74

Tablante, N.L., Vaillancourt, J.P. and Julian, R.J. 1994. Necrotic, haemorrhagic, hepatomegalic hepatitis associated with vasculitis and amyloidosis in commercial laying hens. Avian Pathol., $23: 725-732$.

Trott K.A., Giannitti F., Rimoldi G., Hill A., Woods L., Barr B., Anderson M., and Mete A.2014. Fatty liver hemorrhagic syndrome in the backyard chicken: A retrospective histopathologic case series. Vet. Pathol., 51(4): 787-795.

Whitehead C.C. 1979. Nutritional and metabolic aspects of fatty liver disease in poultry. Vet. Q., 1(3): 150-157.

Yang F., Ruan J., Wang T., Luo J., Cao H., Song Y. Huang J. and Hu G. 2017. Improving effect of dietary soybean phospholipids supplement on hepatic and serum indexes relevant to fatty liver hemorrhagic syndrome in laying hens. Anim. Sci. J., 88(11): 1860-69.

Yousefi M., Shivazad M. and SohrabiHaghdoost I. 2005. Effect of dietary factors on induction of fatty liver hemorrhagic syndrome and its diagnostic methods with use of serum and liver parameters in laying hens. Int. J. Poult. Sci., 4(8): 468-72.

\section{How to cite this article:}

Samir Dey, M.C. Pakhira, Kunal Batabyal, Devi Prasad Isore and Indranil Samanta. 2018. Concurrent Occurrence of Fatty Liver Haemorrhagic Syndrome (FLHS) and Colisepticaemia in a Broiler Breeder Flock. Int.J.Curr.Microbiol.App.Sci. 7(09): 185-189.

doi: https://doi.org/10.20546/ijcmas.2018.709.023 